Artikel Penelitian

\title{
Gambaran Karsinoma Prostat di RSUP Dr. M. Djamil Padang Tahun 2010-2013
}

Muhammad lqbal Andreas ${ }^{1}$, Alvarino ${ }^{2}$, Noza Hilbertina ${ }^{3}$

\begin{abstract}
Abstrak
Karsinoma prostat merupakan kasus neoplasia yang kedua tersering ditemukan pada pria dan tersering kelima dari kasus keganasan pada pria dan wanita. Tujuan penelitian ini adalah mengetahui distribusi kasus karsinoma prostat berdasarkan umur, kadar PSA (Prostate Specific Antigen), metode diagnostik, derajat histopatologis (skor Gleason), stadium dan tatalaksana pada pasien karsinoma prostat di Rumah Sakit Umum Pusat (RSUP) Dr. M. Djamil Padang. Metode penelitian ini adalah deskriptif dengan menggunakan data rekam medik di RSUP Dr. M. Djamil Padang periode 1 Januari 2010 sampai 31 Desember 2013. Didapatkan hasil sebanyak 51 kasus pada periode tersebut. Penderita terbanyak ditemukan pada rentang usia $70-79$ tahun, yaitu sebanyak $39,22 \%$. Sebagian besar kasus $(49,02 \%)$ memiliki kadar PSA $>20 \mathrm{ng} / \mathrm{ml}$. Hampir seluruh kasus $(94,12 \%)$ karsinoma prostat ditemukan secara insidental melalui hasil kerokan TURP (Transurethral resection of the prostate) dan sisanya ditegakkan melalui biopsi. Skor Gleason yang terbanyak adalah skor 5-7 (moderately differentiated) sebanyak 45,10\%. Pada kelompok usia 5059 tahun, karsinoma prostat terbanyak dengan skor 5-7 (moderately differentiated); kelompok usia 60-69 tahun terbanyak skor 8-10 (poorly differentiated); kelompok usia 70-79 tahun terbanyak skor 5-7 (moderately differentiated); dan kelompok usia 80-89 tahun terbanyak skor 8-10 (poorly differentiated). Hanya terdapat 7,84\% kasus yang dapat ditentukan stadiumnya yang seluruhnya sudah stadium 4 . Dari seluruh kasus hanya $23,53 \%$ kasus yang didapatkan oleh peneliti data mengenai tatalaksana yang dilakukan setelah dilakukan TURP. Dari $23,53 \%$ kasus tersebut, seluruhnya dilanjutkan dengan terapi hormonal, 19,61\% kasus diberikan melalui injeksi antiandrogen, 3,92\% kasus dilakukan melalui Orkidektomi.
\end{abstract}

Kata kunci: karsinoma prostat, usia, kadar PSA, metode diagnostik, skor Gleason

\section{Abstract}

Prostate carcinoma is the second most common neoplasia cases in men and the fifth most common malignancy in men and women. The objective of this study was to identified the distribution of carcinoma prostate's cases based on age, PSA levels, diagnostic methods, histopathologic grade, staging, and treatment in Dr. M. Djamil General Hospital in Padang. The method of this study was descriptive used data from medical record of Dr. M. Djamil General Hospital during January 1, 2010 until December 31, 2013. The result showed 51 cases found on that period. Most of the cases (39.22\%) were observed in the 70-79 years age group. Most of the cases (49.02\%) had PSA levels $>20 \mathrm{ng} / \mathrm{ml}$. Almost all cases (94.12\%) of carcinoma prostate found incidentally by TURP specimens and the rest by biopsy specimens. Gleason score of 5-7 (moderately differentiated) was found in most cases (45.10\%). In the 50-59 years age group, the majority of cases had Gleason score of 5-7 (moderately differentiated), the 60-69 years age group had score of 8-10 (poorly differentiated), the 70-79 years age group had score of 5-7 (moderately differentiated), and the 80-89 years age group had score of 8-10 (poorly differentiated). Only $7.84 \%$ of cases can be staged and all the cases had already in stage 4 . Of all cases, only $23.53 \%$ data regarding the treatment after TURP were obtained. Entire cases were followed by hormonal therapy, $19.61 \%$ of cases were given by antiandrogens injection, $3.92 \%$ of cases were done through surgery (orchidectomy).

Keywords: prostate carcinoma, age, PSA, diagnostic methods, gleason score 
Affiliasi penulis: 1. Prodi Profesi Dokter FK Unand (Fakultas Kedokteran Universitas Andalas Padang), 2. Bagian Urologi FK Unand, 3. Bagian Patologi Anatomi FK Unand

Korespondensi: Muhammad lqbal Andreas; Email: andreas.m.iqbal@gmail.com, Telp: +6285265946170

\section{PENDAHULUAN}

Karsinoma prostat adalah keganasan yang berasal dari epitel kelenjar prostat. ${ }^{1}$ Karsinoma prostat berada pada urutan keenam keganasan penyebab kematian pada pria $(6,1 \%)$, dengan perkiraan kematian mencapai 258.000 pada tahun 2008, dan merupakan keganasan kedua tersering ditemukan pada laki-laki (899.000 kasus baru, 13,6 \% dari total seluruh kasus keganasan pada laki-laki). ${ }^{2}$ Data jumlah kasus karsinoma prostat masih belum tercatat lengkap di Indonesia. Tiga pusat pendidikan Urologi (Jakarta, Bandung, dan Yogyakarta) mencatat 761 kasus dalam 5 tahun terakhir. Pada kurun waktu 2004-2011 ditemukan 375 kasus karsinoma prostat di Rumah Sakit Umum Pusat Dr. Hasan Sadikin, Bandung. ${ }^{3}$ Jumlah penderita karsinoma prostat di Rumah Sakit Umum Pusat Nasional Dr. Cipto Mangunkusumo dan Rumah Sakit Kanker Dharmais tahun 2001-2006 meningkat sebanyak dua kali dibandingkan tahun 1995-2000, dengan jumlah penderita rata-rata pertahun adalah 70-80 kasus baru/tahun. ${ }^{4}$ Guideline nasional maupun data kejadian untuk karsinoma prostat di Indonesia pada saat penelitian ini dilakukan masih belum tersedia. Tidak meratanya penyebaran fasilitas maupun tenaga ahli urologi di berbagai wilayah Indonesia menyebabkan masih terdapatnya perbedaan dalam mendiagnosis dan menatalaksana pasien karsinoma prostat. Berdasarkan hal tersebut, perlu dilakukan penelitian mengenai bagaimana gambaran karsinoma prostat di RSUP M.Djamil Padang tahun 2010-2013.

\section{METODE}

Penelitian ini merupakan penelitian deskriptif dengan desain penelitian retrospektif. Penelitian dilakukan di Bagian Rekam Medik RSUP Dr. M. Djamil Padang Februari 2014-Maret 2014.

Populasi penelitian adalah seluruh pasien karsinoma prostat yang terdata di rekam medis RSUP
Dr. M. Djamil Padang periode 1 Januari 2010-31 Desember 2013. Sampel pada penelitian ini diambil dengan teknik total sampling yaitu seluruh populasi dinyatakan sebagai sampel.

Data yang diambil adalah umur penderita, metode diagnostik, kadar PSA, skor Gleason, Stadium dan tatalaksana. Pengolahan data dilakukan secara manual, dilakukan editing terhadap semua variabel yang diteliti kemudian dihitung jumlahnya dengan cara tabulasi. Data dianalisa dengan cara menentukan masing-masing variabel yang akan diteliti, kemudian disajikan dalam tabel distribusi frekuensi.

\section{HASIL}

Didapatkan 51 pasien karsinoma prostat selama periode 1 Januari 2010 sampai 31 Desember 2013 melalui data rekam medik pasien.

Tabel 1. Distribusi karsinoma Prostat menurut usia

\begin{tabular}{ccc}
\hline Usia (Tahun) & $\begin{array}{c}\text { Jumlah } \\
\text { (Orang) }\end{array}$ & Persentase (\%) \\
\hline $50-59$ & 8 & 15,69 \\
$60-69$ & 14 & 27,45 \\
$70-79$ & 20 & 39,22 \\
$80-89$ & 9 & 17,65 \\
\hline Jumlah & 51 & 100 \\
\hline
\end{tabular}

Penderita terbanyak ditemukan pada rentang usia 70-79 tahun, yaitu sebanyak 20 kasus (39,22\%) dan tidak ditemukan penderita pada usia $\leq 49$ tahun dan $\geq 90$ tahun.

Tabel 2. Distribusi karsinoma prostat berdasarkan kadar PSA inisial

\begin{tabular}{ccc}
\hline $\begin{array}{c}\text { PSA Inisial } \\
\text { (ng/ml) }\end{array}$ & Jumlah & $\%$ \\
\hline $0-4$ & 2 & 3,92 \\
$4-20$ & 6 & 11,76 \\
$>20$ & 25 & 49,02 \\
Tidak diketahui & 18 & 35,29 \\
\hline Jumlah & 51 & 100 \\
\hline
\end{tabular}

Pada 51 kasus yang diteliti, hanya 33 kasus yang diperiksa kadar PSA dan sebagian besar kasus tersebut $(49,02 \%)$ memiliki kadar $>20 \mathrm{ng} / \mathrm{ml}$. 
Tabel 3. Distribusi karsinoma prostat berdasarkan metode diagnostik

\begin{tabular}{lcc}
\hline \multicolumn{1}{c}{ Metode Diagnostik } & Jumlah & $\%$ \\
\hline Hasil kerokan TURP & 48 & 94,12 \\
Biopsi & 3 & 5,88 \\
\hline Jumlah & 51 & 100 \\
\hline
\end{tabular}

Dari 51 kasus yang diteliti, 48 kasus $(94,12 \%)$ ditemukan secara insidental melalui hasil kerokan TURP dan 3 kasus (5,88\%) ditegakkan melalui biopsi.

Tabel 4. Distribusi kasus karsinoma prostat berdasarkan derajat histopatologi (skor Gleason)

\begin{tabular}{lcc}
\hline \multicolumn{1}{c}{ Skor Gleason } & Jumlah & $\%$ \\
\hline 2-4 (well differentiated) & 4 & 7,84 \\
5-7 (moderately differentiated) & 23 & 45,10 \\
8-10 (poorly differentiated) & 21 & 41,18 \\
Tidak diketahui & 3 & 5,88 \\
\hline \multicolumn{1}{c}{ Jumlah } & 51 & 100
\end{tabular}

Berdasarkan Tabel 4 dari 51 kasus yang diteliti, 48 kasus yang ada dicantumkan skor Gleason. Skor Gleason yang terbanyak adalah skor 5-7 (moderately differentiated) yaitu 23 kasus $(45,10 \%)$.

Tabel 5. Distribusi derajat histopatologi (skor Gleason) berdasarkan usia

\begin{tabular}{lcccccc}
\hline \multirow{2}{*}{ Usia } & \multicolumn{7}{c}{ Skor Gleason } \\
\cline { 2 - 8 } & \multicolumn{2}{c}{$\mathbf{2 - 4}$} & \multicolumn{3}{c}{$\mathbf{5 - 7}$} & \multicolumn{2}{c}{$\mathbf{8 - 1 0}$} \\
\cline { 2 - 8 } & Jumlah & $\%$ & Jumlah & $\%$ & Jumlah & $\%$ \\
\hline $50-59$ & 1 & 1,96 & 5 & 9,8 & 2 & 3,92 \\
$60-69$ & 1 & 1,96 & 5 & 9,8 & 8 & 15,69 \\
$70-79$ & 2 & 3,92 & 12 & 23,53 & 5 & 9,8 \\
$80-89$ & - & - & 1 & 1,96 & 6 & 11,76 \\
\hline Jumlah & 4 & 8,33 & 23 & 45,10 & 21 & 41,18 \\
\hline
\end{tabular}

Pada 48 kasus yang ada dicantumkan skor Gleason, pada kelompok usia 50-59 tahun, karsinoma prostat terbanyak dengan skor 5-7 (moderately differentiated); pada kelompok usia 60-69 tahun, karsinoma prostat terbanyak dengan skor 8-10 (poorly differentiated); pada kelompok usia 70-79 tahun, karsinoma prostat terbanyak dengan skor 5-7 (moderately differentiated); dan pada kelompok usia 80-89 tahun, karsinoma prostat terbanyak dengan skor 8-10 (poorly differentiated).
Tabel 6. Distribusi kasus karsinoma prostat menurut stadium TNM

\begin{tabular}{lccccc}
\hline \multicolumn{1}{c}{ TNM } & $\begin{array}{c}\text { Ju } \\
\text { ml } \\
\text { ah }\end{array}$ & $\begin{array}{c}\text { Stadi } \\
\text { um }\end{array}$ & $\begin{array}{c}\text { Ju } \\
\text { ml } \\
\text { ah }\end{array}$ & \% \\
\hline T1aN0M0G1 & - & - & I & - & - \\
\hline T1aN0M0G2,G3-4 & - & - & & & \\
T1b,cN0M0SemuaG & - & - & II & - & - \\
T1T2N0M0SemuaG & - & - & & & \\
\hline T3N0M0SemuaG & - & - & III & - & - \\
\hline T4N0M0SemuaG & - & - & & & \\
SemuaTN1M0SemuaG & 1 & 1,96 & IV & 4 & 7,84 \\
SemuaTSemuaNM1 & 3 & 5,88 & & & \\
SemuaG & & & & & \\
\hline Tidak diketahui & 47 & 92,16 & & 47 & 92,16 \\
\hline Jumlah & 51 & 100 & & 51 & 100 \\
\hline
\end{tabular}

Berdasarkan Tabel 6, dari 51 kasus yang diteliti, hanya 4 kasus $(7,84 \%)$ yang dapat ditentukan stadiumnya yang seluruhnya sudah stadium 4 .

Tabel 7. Distribusi karsinoma prostat berdasarkan tatalaksana

\begin{tabular}{lcc}
\hline Tatalaksana & Jumlah & $\%$ \\
\hline Terapi Hormonal & 12 & 23,53 \\
Tidak diketahui & 39 & 76,47 \\
\hline Jumlah & 51 & 100 \\
\hline
\end{tabular}

Pada 51 kasus yang diteliti, hanya 12 kasus yang didapatkan data mengenai tatalaksana yang dilakukan setelah dilakukan TURP. Dari 12 kasus, seluruhnya dilanjutkan dengan terapi hormonal, 10 kasus diberikan melalui injeksi yaitu dengan antiandrogen, 2 kasus dilakukan melalui operasi, yaitu Orkidektomi.

\section{PEMBAHASAN}

Pada penelitian ini, sejak 1 Januari 2010 sampai 31 Desember 2013 didapatkan sebanyak 51 kasus karsinoma prostat di RSUP Dr. M. Djamil Padang. Kasus terbanyak terdapat pada selang usia 70-79 dengan persentase sebesar $39,22 \%$, disusul selang usia 60-69 sebesar 27,45\%, $80-89$ sebesar $17,65 \%$, dan $50-59$ sebesar $15,69 \%$. Hal ini sejalan dengan data dari Indonesian Society of Urologic Oncology (ISUO) melaporkan selama periode 20062010 dari 971 penderita karsinoma prostat, terbanyak 
pada selang usia 70-79 tahun sebesar $37,6 \%{ }^{4}$ Zhou et al melaporkan salah satu studi yang juga menemukan insidensi karsinoma prostat terbanyak pada selang usia $70-79$ sebesar $45,5 \%$, disusul selang usia 60-69 sebesar $34,3 \%$, dan $50-59$ sebesar $23,4 \%{ }^{5}$

Pada penelitian ini tidak ditemukan pasien yang berusia di bawah 50 tahun. Karsinoma prostat memang jarang ditemukan pada pria di bawah usia 50 tahun. ${ }^{1}$ Mc Avoy et al melaporkan hampir $90 \%$ dari keseluruhan kasus baru terjadi pada pria dengan usia 60 tahun ke atas, dan dua per tiga pria yang meninggal karena karsinoma prostat berusia lebih dari 75 tahun. Risiko terdiagnosis karsinoma prostat memang sangat terkait dengan faktor usia, dimana pada pria berusia 70-79 tahun memiliki risiko hampir 7 kali lebih tinggi dibandingkan dengan pria berusia 5059 tahun dan risiko kematiannya juga meningkat menjadi 21 kali lebih tinggi. Namun kematian mendadak yang disebabkan oleh karsinoma prostat lebih cenderung terjadi pada pria yang terdiagnosis karsinoma prostat pada usia 50-an dibandingkan dengan yang terdiagnosis pada usia 70an. ${ }^{6}$

Dari 51 pasien karsinoma prostat hanya 33 pasien yang didapatkan data kadar PSA inisialnya. Kadar PSA 0-4 ng/ml ditemukan sebanyak 2 kasus (3,92\%), 4-20 $\mathrm{ng} / \mathrm{ml}$ ditemukan sebanyak 6 kasus $(11,76 \%),>20 \mathrm{ng} / \mathrm{ml}$ ditemukan pada 25 kasus $(49,2 \%)$ dan 18 kasus $(35,29 \%)$ tidak diketahui. Menurut klinisi, adanya kasus yang tidak dicantumkan kadar PSA inisial ini disebabkan oleh keterbatasan zat reagen PSA di RSUP Dr. M. Djamil Padang. Banyak pasien datang sudah dengan keadaan obstruksi, klinisi biasanya memutuskan untuk segera memberikan tatalaksana terhadap keluhan obstruksi (TURP) guna mengurangi keluhan si pasien, daripada menunggu zat reagen PSA tersedia kembali.

Secara universal, indikasi biopsi prostat adalah kelainan pada colok dubur atau peningkatan PSA $>4$ $\mathrm{ng} / \mathrm{ml}^{7}$ Di Asia masih banyak urologis yang menggunakan nilai $P S A \geq 10 \mathrm{ng} / \mathrm{ml}$ sebagai nilai cut off untuk indikasi biopsi prostat. Hal ini didasari oleh pengalaman para urologis tersebut yang jarang menemukan hasil biopsi positif karsinoma prostat pada pasien dengan kadar PSA $\leq 10 \mathrm{ng} / \mathrm{ml} .{ }^{8}$ Monoarfa et al menemukan para spesialis urologi di Indonesia juga masih memiliki pendapat yang berbeda-beda mengenai nilai cut-off PSA, sebanyak $40 \%$ spesialis urologi memakai cut-off $P S A>10 \mathrm{ng} / \mathrm{ml}$ dan sebanyak $29 \%$ memakai angka PSA $>4 \mathrm{ng} / \mathrm{ml}$. Penelitian tersebut merekomendasikan penggunaan nilai cut-off PSA yang lebih tinggi, yaitu $>20 \mathrm{ng} / \mathrm{ml}$ untuk evaluasi karsinoma prostat pada pasien dengan LUTS. ${ }^{9}$

Pada 51 pasien karsinoma prostat, 48 kasus $(94,12 \%)$ ditemukan secara insidental melalui hasil kerokan TURP dan 3 kasus $(5,88 \%)$ melalui biopsi. Seluruh sampel pada penelitian ini datang sudah dengan keluhan obstruksi, karena itu seluruh sampel diberi tindakan TURP untuk menghilangkan keluhan obstruksinya. Metode standar untuk mendeteksi karsinoma prostat saat ini adalah biopsi yang dipandu dengan TRUS. ${ }^{1}$ TRUS probe tidak tersedia di RSUP Dr. M. Djamil Padang sampai saat penelitian ini dilakukan, karena itu biopsi hanya dilakukan pada 3 kasus yang klinisi temukan tanda-tanda tumor pada pemeriksaan colok dubur. Kasus karsinoma prostat masih sering ditemukan secara insidental melalui hasil kerokan TURP di negara-negara berkembang seperti di Asia termasuk di Indonesia, hal ini disebabkan oleh kurangnya fasilitas diagnostik (TRUS probe dan needle) dan kondisi pasien yang datang sudah dengan retensi urin. ${ }^{8}$

Skor Gleason yang terbanyak pada penelitian ini adalah skor 5-7 (moderately differentiated) sebanyak 23 kasus (45,10\%), disusul skor 8-10 (poorly differentiated) sebanyak 21 kasus $(41,18 \%)$ dan skor 2-4 (well differentiated) sebanyak 4 kasus (7,84\%). Pada kelompok usia 50-59 tahun, karsinoma prostat terbanyak dengan skor 5-7 (moderately differentiated); pada kelompok usia 60-69 tahun, karsinoma prostat terbanyak dengan skor 8-10 (poorly differentiated); pada kelompok usia 70-79 tahun, karsinoma prostat terbanyak dengan skor 5-7 (moderately differentiated); dan pada kelompok usia 80-89 tahun, karsinoma prostat terbanyak dengan skor 8-10 (poorly differentiated).

Skor Gleason saat ini merupakan metode yang paling banyak digunakan di dunia untuk menentukan derajat histopatologi karsinoma prostat, namun sampai saat ini penelitian mengenai hubungan skor Gleason 
dengan usia pasien saat terdiagnosis karsinoma prostat masih banyak terdapat perbedaan. ${ }^{10}$ Penelitian Zhou et al menemukan bahwa pada ras Afro Amerika terdapat kecendrungan peningkatan skor Gleason pada pria dengan usia lanjut dan pada ras Kaukasia tidak, namun menariknya mereka menemukan bahwa pada usia di bawah 50 tahun sama-sama terdapat skor Gleason yang tinggi pada kedua ras. ${ }^{5}$ Penelitian Putriyuni pada laboratorium patologi anatomi yang ada di Sumatera Barat menemukan distribusi semua skor Gleason sama pada usia $\leq 50$ tahun, kelompok usia 51-60 tahun paling banyak well differentiated $(42,86 \%)$, sedangkan kelompok usia 61-70 tahun, 7180 , tahun dan 81-90 tahun paling banyak adalah poorly differentiated yang masing-masing 46,03\%, $50 \%$, dan $62,50 \%$. Pada penelitian tersebut menunjukkan bahwa semakin meningkat usia, skor Gleason cenderung lebih tinggi. Namun pada penelitian tersebut sudah menggunakan sistem Gleason ISUP (International Society of Urological Pathology) 2005 yang telah direvisi sedangkan pada penelitian ini masih mengacu pada WHO (World Health Organization) $2004 .^{11}$

Stadium merupakan salah satu dasar dalam mempertimbangkan jenis pengobatan dan prognosis pasien bersama dengan skor Gleason dan nilai PSA. ${ }^{7}$ Namun dari 51 kasus, hanya empat kasus yang dapat ditentukan stadiumnya. Hal ini dikarenakan untuk menentukan derajat kelenjar getah bening $(\mathrm{N})$ harus dilakukan diseksi kelenjar getah bening baik secara operasi terbuka atau laparoskopi yang menambah lama waktu operasi, beban biaya dan morbiditas, sehingga banyak pasien yang menolak. Begitu juga dengan derajat metastasis $(M)$, karsinoma prostat yang biasanya bermetastasis ke tulang dapat diketahui melalui pemeriksaan bone scan. ${ }^{7}$ Fasilitas bone scan sampai saat peneliti melakukan penelitian ini masih belum tersedia di RSUP Dr. M. Djamil Padang. Klinisi biasanya menyarankan kepada pasien untuk dirujuk ke fasilitas yang lebih lengkap, namun pasien biasanya menolak dengan berbagai alasan. Menurut klinisi, empat kasus dapat ditentukan stadium nya karena ditemukan secara tidak sengaja derajat getah bening $(\mathrm{N})$ dan derajat metastasis $(\mathrm{M})$ melalui CT Scan dan bone survey.
Prostatektomi radikal merupakan terapi kuratif utama pada karsinoma prostat terlokalisir namun tindakan ini belum banyak dilakukan di Indonesia karena beberapa hal, seperti jumlah pasien tidak sebanyak di negara barat, pasien datang lebih banyak pada stadium lanjut, sumber daya manusia masih terbatas, dan risiko penyulit/efek samping berupa perdarahan, inkontinesia urin, serta disfungsi ereksi. ${ }^{3}$ Umbas et al juga mengatakan terapi radikal untuk pasien stadium dini seperti prostatektomi radikal dan radioterapi masih sangat jarang dilakukan di Indonesia. ${ }^{8}$ Pada penelitian ini, dari 51 kasus yang diteliti hanya 12 kasus (23,53\%) yang didapatkan oleh peneliti data mengenai tatalaksana yang diberikan setelah dilakukan TURP. Seluruhnya dilanjutkan dengan terapi hormonal, 10 kasus diberikan melalui injeksi yaitu dengan antiandrogen, 2 kasus dilakukan melalui operasi, yaitu Orkidektomi. Menurut klinisi banyaknya kasus yang tidak diketahui tatalaksananya disebabkan pasien tidak datang lagi konsultasi ke dokter setelah dipulangkan pasca TURP. Penelitian di Rumah Sakit Umum Daerah Moewardi Solo, periode 2000-2006 dari 30 kasus karsinoma prostat, sebanyak 11 kasus TURP dilanjutkan dengan terapi hormonal melalui injeksi dan 7 kasus dilanjutkan dengan kombinasi terapi hormonal melalui injeksi dan operasi. ${ }^{4}$ Umbas et al mengatakan terapi hormonal dan TURP masih merupakan modalitas terapi yang paling sering dipilih oleh ahli urologis di Indonesia karena kondisi pasien yang datang sudah dengan stadium lanjut. ${ }^{8}$ Pada penelitian ini terdapat 25 pasien yang memiliki kadar PSA $>20 \mathrm{ng} / \mathrm{ml}$ dan 19 diantaranya memiliki kadar PSA $>100 \mathrm{ng} / \mathrm{ml}$. Terapi hormonal merupakan baku emas pengobatan karsinoma prostat stadium lanjut. ${ }^{7}$ kadar PSA inisial lebih dari $100 \mathrm{ng} / \mathrm{ml}$ menggambarkan pasien sudah stadium lanjut. ${ }^{12}$ Menurut klinisi hal ini menjadi salah satu dasar dalam pemilihan terapi hormonal pada sampel penelitian ini.

\section{SIMPULAN}

Skor Gleason yang terbanyak adalah skor 5-7 (moderately differentiated).

Pada kelompok usia 50-59 tahun, karsinoma prostat terbanyak ialah dengan skor 5-7 (moderately 
differentiated); pada kelompok usia 60-69 tahun, karsinoma prostat terbanyak dengan skor 8-10 (poorly differentiated); pada kelompok usia 70-79 tahun, karsinoma prostat terbanyak dengan skor 5-7 (moderately differentiated); dan pada kelompok usia 80-89 tahun, karsinoma prostat terbanyak dengan skor 8-10 (poorly differentiated).

\section{DAFTAR PUSTAKA}

1. Epstein JI, Helpap B, Algaba F, Humphrey PA, Allsbrook WC, Iczkowski KA, et al. Acinar Adenocarcinoma. Dalam: Eble JN, Sauter G, Epstein JI, Sesterhenn IA. Pathology and genetics of tumours of the urinary system and male genital organs. Lyon: IARC Press. 2004.hlm.160-92.

2. International Agency for Research on Cancer (IARC) GLOBOCAN. Prostate cancer incidence and mortality worldwide. 2008 (diunduh 9 Desember 2013). Tersedia dari: URL: HYPERLINK http://globocan.iarc.fr/factsheets/cancers/prostate.a $\underline{s p}$

3. Safriadi F. Prostatektomi radikal: morbiditas dan mortalitas di RSUP dr. Hasan Sadikin Bandung. Indonesian Journal of Cancer. 2013;7(1):23-8.

4. Umbas R, Hardjowijoto S, Mochtar CA, Safriadi F, Djatisoesanto W, Soedarso MA, et al. Panduan penatalaksanaan kanker prostat 2011. Jakarta: Ikatan Ahli Urologi Indonesia. 2011.hlm.1-2.

5. Zhou X, Bigler SA, dan Pound CR. Age Disparities in Diagnosis of Prostate Cancer Between African
Americans and Caucasians. Ageing Int. 2011;37; 186-94.

6. Mc Avoy BR, Steginga SK, dan Pinnock C. The early detection of prostate cancer in general practice: Supporting patient choice. Nzjp. 2006; 33; (1)49-57.

7. Umbas R. Penanganan kanker prostat saat ini dan beberapa perkembangan baru. Indonesian Journal of Cancer. 2008;3;114-9.

8. Umbas R, Mochtar CA, dan Rahardjo HE. Current Status of Prostate Cancer in Asia. Indonesian Journal of Cancer. 2011;5(1):21-4.

9. Monoarfa RA, Hamid AR, Mochtar CA, Umbas R. Diagnosis kanker prostat dalam perspektif spesialis urologi Indonesia: sebuah survei kuesioner. Indonesian Journal of Cancer. 2012;6(3):97-104.

10. Peschel RE, Khan A, Colberg J, dan Wilson LD. The Effect of age on prostate implantation results. The Cancer Journal 12,4; ProQuest Nursing \& Allied Health Source. 2006;305.

11. Putriyuni A. Profil adenokarsinoma prostat di laboratorium patologi anatomi Sumatera Barat tahun 2010-2012. Penelitian Pendahuluan. Bagian Patologi Anatomi Fakultas Kedokteran Universitas Andalas. 2014

12. Etriyel, Umbas R, Mochtar CA, dan Santoso RB. Prostate specific antigen (PSA) inisial $\geq 100 \mathrm{ng} / \mathrm{ml}$ menggambarkan stadium lanjut dan rendahnya survival kanker prostat. Indonesian Journal of Cancer. 2011;5(2):57-60. 